\title{
A AGROINDÚSTRIA FAMILIAR COMO ESTRATÉGIA DE REPRODUÇ̃̃O SOCIOECONÔMICA E DE EMANCIPAÇÃO FEMININA EM LINHARES, ESPPÍRITO SANTO ${ }^{1}$
}

\author{
Alessandra Maria da Silva² \\ Erika Vanessa Moreira Santos ${ }^{3}$ \\ Niraldo José Ponciano ${ }^{4}$
}

\begin{abstract}
RESUMO
Este trabalho teve por objetivo entender a importância da agroindústria artesanal de derivados do leite, como estratégia de reprodução socioeconômica e de emancipação das mulheres na agricultura familiar do município de Linhares, Espírito Santo. A pesquisa qualitativa foi realizada entre os meses de fevereiro a maio de 2016, no município de Linhares-ES, envolvendo dez famílias participantes de projetos da Extensão Rural oficial daquele município. Foram aplicadas entrevistas semiestruturadas com as dez mulheres produtoras de queijo integrantes das famílias que compuseram as unidades de análise. Os resultados foram transcritos, sistematizados e submetidos à análise de conteúdo. A pluriatividade para-agrícola, por meio da agroindustrialização da produção de leite, se mostrou como uma estratégia de reprodução socioeconômica das famílias diante de crises financeiras e contribuiu para elevar a autonomia e a autoestima das mulheres entrevistadas. No entanto, a autonomia financeira e decisória feminina se mostrou limitada pela dominação masculina no meio rural.
\end{abstract}

Palavras-chave: agricultura familiar, autonomia financeira feminina, pluriatividade, produção artesanal de queijos.

\section{THE FAMILY AGROINDUSTRY AS A STRATEGY FOR SOCIOECONOMIC REPRODUCTION AND FEMININE EMANCIPATION IN LINHARES, ESPÍRITO SANTO, BRAZIL}

\begin{abstract}
The objective of this study was to analyze the importance of the handmade dairy agroindustry as a strategy for economic reproduction and emancipation for women farming in the municipality of Linhares, north of the State of Espírito Santo, Brazil.

\footnotetext{
${ }^{1}$ A pesquisa contou com o apoio financeiro do Banco do Nordeste do Brasil (BNB).

2 Graduada em Medicina Veterinária; Mestre em Medicina Veterinária (UFV). Doutoranda em Produção Vegetal/Engenharia e Economia na Agricultura (UENF); Agente de Extensão em Desenvolvimento Rural do Instituto Capixaba de Pesquisa, Assistência Técnica e Extensão Rural (INCAPER). E-mail: alessandravet92@gmail.com Professora do Programa de Pós-Graduação em Geografia da Universidade Federal Fluminense (UFF/Campos dos Goytacazes). E-mail: evmgeo@yahoo.com.br

${ }^{4}$ Graduado em Agronomia; Mestre em Economia Rural; Doutor em Economia Aplicada (UFV). Professor no Programa de Pós-Graduação em Produção/Engenharia e Economia na Agricultura da Universidade Estadual do Norte Fluminense Darcy Ribeiro (UENF). E-mail: ponciano@uenf.br
}

${ }^{3}$ Graduada em Geografia; Mestre em Geografia; Doutora em Geografia (UNESP - Presidente Prudente).
\end{abstract}


The qualitative research was carried out between February and May of 2016, in the municipality of Linhares, involving ten families participating in projects of the official Rural Extension. Semi-structured interviews were applied with the ten female cheese producers from the families that composed the analysis units. The results were transcribed, systematized and submitted to content analysis. The agricultural paraagricultural pluriactivity through the handmade dairy products was shown as a strategy for economic reproduction of families in the face of financial crises and contributed to increase the autonomy and self-esteem of the women interviewed. However, female financial and decision-making autonomy was limited by male domination in rural areas.

Keywords: cheese handmade production, family farm, female financial autonomy, pluriactivity.

\section{INTRODUÇÃO}

A agroindústria familiar rural tem se apresentado como estratégia de reprodução socioeconômica para agricultores familiares diante das transformações no espaço rural ocorridas nos últimos cinquenta anos. Embora a produção de derivados do leite não seja uma atividade recente, para muitas famílias agricultoras, a atividade - que antes era apenas para o consumo da família - passou a ser uma fonte geradora de renda, alcançando mercados antes não explorados.

As mudanças estruturais ocorridas no espaço rural, que contribuíram para as novas formas de relações econômicas e sociais no campo, advêm do período em que ocorreu o processo denominado de "modernização da agricultura", que compreendeu especialmente as décadas de 1960 a 1980, no Brasil. Esse período consolidou o modelo agroindustrial, por meio de cadeias produtivas fortemente centradas em produção de commodities e foi responsável pela redução da produção diversificada da agricultura familiar, resultando em grandes impactos socioeconômicos tanto no espaço rural quanto no urbano (MARTINE, 1991). Muitas famílias agricultoras que permaneceram no espaço rural se sucumbiram ao sistema capitalista, rendendo-se ao modelo de integração contratual da produção familiar com as grandes agroindústrias, voltando-se para a especialização da produção e criando um ciclo de dependência do modelo imposto.

Diversas políticas públicas estimularam a produção em escala para o abastecimento das agroindústrias, como ocorreu e ainda ocorre no setor produtivo de leite e de derivados. Nesse setor, são exigidos volume e qualidade do leite aos produtores rurais, os quais se tornam dependentes da agroindústria. Quando não organizados em cooperativas ou associações, os agricultores familiares se veem reféns da agroindústria, sendo incapazes de negociar previamente 0 valor da produção e de garantir a captação do leite produzido.

Como forma de resistência ao modelo capitalista hegemônico, o setor informal de produção de alimentos, como o processamento artesanal de derivados do leite, passa a ocupar um espaço significativo nos mercados regionais. As agroindústrias familiares possuem, portanto, um importante papel no desenvolvimento rural por se apresentar como uma estratégia de produção e reprodução socioeconômica para as famílias rurais, uma vez que as agroindústrias agregam valor à produção, ampliando o número de produtos ofertados no comércio local, diminuindo a dependência de mercadorias exógenas e a transferência monetária para outras regiões, contribuindo para o fortalecimento das economias locais. E como forma de organização da produção das famílias rurais, as 
agroindústrias familiares acabam por atribuir aos atores envolvidos novos papéis e tarefas.

Nesse cenário da agroindústria familiar se destaca o trabalho das mulheres que, tradicionalmente, têm sido as principais responsáveis pela produção de doces, pães, bolos, biscoitos, embutidos, derivados do leite, dentre outros. Cabe aqui, então, também se discutir as relações de gênero e o processo de emancipação financeira das mulheres agricultoras.

A organização familiar rural está direta e historicamente relacionada à divisão sexual do trabalho, no qual o homem é responsável pela produção e a mulher pela reprodução. Enquanto cabe ao homem a responsabilidade pela atividade produtiva agropecuária, cabe à mulher as atividades domésticas (como o cuidado da casa e dos filhos) e do entorno da casa (como pequenas criações e hortas). Além disso, também a produção de alimentos processados, como doces, embutidos e derivados do leite, tradicionalmente, faz parte da alimentação da família e geralmente está sob a responsabilidade da mulher. $\mathrm{Na}$ produção para autoconsumo, o excedente é comercializado e, geralmente, o recurso monetário obtido é destinado às pequenas despesas do lar sendo administrado pela mulher (BRUMER, 2004).

No entanto, a partir do momento em que as famílias rurais entendem a agroindústria como uma estratégia de reprodução e de adaptação às mudanças socioeconômicas que ocorrem no meio rural, para algumas delas o processamento de alimentos deixa de ser meramente para autoconsumo para ser uma fonte de renda importante para a família. Mesmo assim, o trabalho da mulher não deixou de ser considerado como ajuda no orçamento doméstico e, quando a atividade passa a ser a principal fonte de renda da família, a gestão tende a passar para as mãos do homem (SILIPRANDI, 2015).

No município de Linhares, localizado no norte do Estado do Espírito Santo, têm sido desenvolvidos trabalhos pela Extensão Rural oficial, voltados para o incentivo ao processamento de derivados do leite, objetivando a melhoria das condições microbiológicas dos alimentos e formalização das agroindústrias familiares, com vistas ao fornecimento desses produtos aos programas de compras governamentais, como o Programa de Aquisição de Alimentos (PAA) e a Política Nacional de Alimentação Escolar (PNAE). Nesses trabalhos, a presença de mulheres como responsáveis pela manipulação de alimentos é majoritária. Considerando a importância desse mercado para a agricultura familiar e, especialmente para as mulheres envolvidas no processo, como a agroindústria artesanal de derivados do leite tem contribuído como estratégia de reprodução socioeconômica dessas famílias? Como são as relações familiares e os processos decisórios sobre a gestão de recursos? As agroindústrias artesanais de queijos têm contribuído, de fato, para a emancipação feminina?

Este trabalho teve por objetivo entender a importância da agroindústria artesanal de derivados do leite como estratégia de reprodução socioeconômica familiar e de emancipação econômica de mulheres no município de Linhares, Espírito Santo. Com base nos resultados alcançados, este artigo foi organizado com vistas a abordar temas como as estratégias de reprodução da agricultura familiar por meio da atividade de agroindustrialização, a partir do perfil das famílias e das mulheres, em especial; a importância da renda da atividade de produção de derivados do leite para a autonomia e autoestima das mulheres; as relações de gênero e o processo de decisão intrafamiliar do destino da renda e suas consequências nas expectativas dessas mulheres. 


\section{METODOLOGIA}

A pesquisa, do tipo qualitativa, foi desenvolvida no município de Linhares, norte do Estado do Espírito Santo, entre os meses de fevereiro e maio de 2016.

O campo empírico foi estabelecido a partir de dez propriedades rurais acompanhadas em projetos desenvolvidos pela Extensão Rural oficial local, como unidades de observação de produção de derivados do leite. Nessas unidades de observação, as mulheres são as responsáveis pela produção de queijos e compuseram as unidades de análise deste trabalho.

Foram aplicados roteiros de entrevistas semiestruturadas com as dez mulheres produtoras de queijo das unidades de observação. Buscou-se conhecer a realidade socioeconômica das famílias integrantes da pesquisa e suas estratégias de reprodução; como são estabelecidas as relações de gênero intrafamiliares no processo de decisão na gestão dos recursos da família; como se dá a relação das mulheres com a renda obtida. Como forma de preservar a identidade das mulheres, elas foram codificadas com um nome fictício. Os resultados obtidos foram transcritos, sistematizados, categorizados e submetidos à análise de conteúdo, conforme proposto por Bardin (1977).

\section{RESULTADOS E DISCUSSÃO}

\subsection{A AGROINDÚSTRIA FAMILIAR COMO ESTRATÉGIA DE REPRODUÇÃO SOCIOECONÔMICA}

A agroindústria familiar rural é caracterizada como uma forma de organização em que a família rural produz e processa toda ou parte de sua produção agrícola e/ou pecuária, com vistas a agregação de valor para comercialização. Ainda há que se considerar que a agroindústria familiar apresenta aspectos como a localização no meio rural, a utilização de máquinas e equipamentos para produção em escalas menores, a procedência da matéria prima sendo própria e/ou adquirida de vizinhos, a predominância de mão de obra familiar e a aplicação de processos artesanais próprios (MIOR, 2011).

Para o contexto proposto, de acordo com Redin (2012), o termo "estratégia de reprodução" remete para o campo das relações intrafamiliares e suas formas de desenvolvimento no meio rural, submetidas aos fatores internos (estruturais, saber fazer geracional, relações familiares etc.) e externos (sociais, culturais, políticoinstitucionais, econômicos, religiosos, legais, ambientais etc.) à propriedade. É um processo dinâmico, que pode ser entendido como resultado de decisões tomadas pelas famílias quando influenciadas por diversos elementos no tempo e no espaço, variando de acordo com as particularidades do contexto em que as famílias se inserem e também com a forma de gestão, que pode ser mais integrada ao mercado ou mais autônoma. "Cada realidade na agricultura familiar, pode ser encarada de forma distinta, portanto, com estratégias diversas para conduzir sua reprodução no meio rural" (REDIN, 2012, p. 159).

A diversificação das atividades produtivas é uma importante estratégia de reprodução da agricultura familiar, pois não somente amplia o leque de produtos comercializáveis, como também asseguram a subsistência da família. A diversificação da produção pode ser vista, portanto, como uma forma de resistência ao modelo capitalista que se inseriu no meio rural e pode estar relacionada tanto ao desenvolvimento de atividades agropecuárias quanto não agropecuárias, como a agroindustrialização (SILVA; MENDES, 2015). 
As famílias participantes deste estudo se enquadram nessa característica de diversificação da produção como forma de reprodução familiar. A combinação de múltiplas ocupações dos membros da mesma família, tanto em atividades agropecuárias ou não agropecuárias, desenvolvidas no próprio estabelecimento ou fora dele, caracteriza a pluriatividade da agricultura familiar, conforme proposto por Schneider (2010). Tais famílias são, portanto, pluriativas, pois segundo Schneider (2007), o processamento da produção agrícola com vistas à comercialização caracteriza a pluriatividade do tipo para-agrícola ${ }^{5}$. E, para Schneider (2010), o exercício da pluriatividade depende das decisões dos indivíduos ou das famílias. Portanto, esse processo decisório será um dos objetos de estudo deste trabalho.

\subsection{CARACTERIZAÇÃO DAS ATIVIDADES ECONÔMICAS DAS FAMÍLIAS}

De acordo com as famílias entrevistadas, antes de participarem dos projetos de Extensão Rural, cinco delas já possuíam a agroindústria registrada no Serviço de Inspeção Municipal (SIM), detendo espaço apropriado para produção denominados por elas como "queijarias" -, embora apenas duas realizassem a pasteurização prévia do leite. As demais famílias não tinham acesso ao mercado varejista da área urbana por não possuírem o registro no SIM, comercializando os produtos entre os vizinhos, intermediários e mercados locais.

As famílias apresentavam como principais atividades a cafeicultura, a bovinocultura de leite e a agroindustrialização, mostrando-se pluriativas. Apenas duas famílias apresentavam a atividade de processamento do leite como principal fonte de renda. Das dez famílias participantes, quatro apresentavam pluriatividade intersetorial, de acordo com a tipologia proposta por Schneider (2007), sendo que, em duas delas, as mulheres trabalhavam em escolas rurais e outras duas famílias possuíam comércio no espaço rural.

De acordo com o relato das famílias, após a participação nos projetos de Extensão Rural, verificou-se que três famílias passaram a ter a produção de leite e de derivados como única atividade geradora de renda e outras duas famílias passaram a ter a agroindustrialização como sua principal fonte de renda. Duas famílias produzem derivados do leite de forma sazonal, durante o período de safra, interrompendo a produção em períodos de entressafra, tendo a cafeicultura como principal atividade geradora de renda. No entanto, três famílias abandonaram a atividade de processamento de leite e derivados, tendo a atividade de comércio de produtos agrícolas (compra e venda) e de produtos não agrícolas (material de construção e de irrigação) como principal fonte de renda da família.

Foi possível observar que das quatro mulheres entrevistadas, cujas agroindústrias possuem registro no SIM, três (Marinalva, Joana e Jussara) dedicamse exclusivamente às atividades de produção de leite e de processamento de derivados do leite. Apenas a família de Paulina desenvolve outra atividade agrícola, como a produção de café, e não agrícola, que é o trabalho de Paulina como professora. De acordo com Vinha et al. (2010), a produção de queijo geralmente se torna a atividade principal quando a agroindústria é inspecionada, devido às exigências estruturais, sanitárias e fiscais que demandam tempo e envolvimento de

\footnotetext{
${ }^{5}$ Schneider (2007) propôs uma tipologia para a pluriatividade na agricultura familiar, compondo quatro tipos, que são: pluriatividade tradicional camponesa, voltada para produção para o autoconsumo; pluriatividade intersetorial, que envolve a articulação da agricultura com outros setores da economia, como indústria e comércio; pluriatividade de base agrária, baseada na terceirização de serviços e atividades não-agrícolas geradas no próprio setor agropecuário; e pluriatividade para-agrícola, quer resulta do conjunto de operações e procedimentos necessários para a transformação, beneficiamento ou processamento da produção agrícola e destinado à comercialização.
} 
mais membros da família. Em seus estudos, Vinha et al. (2010) observaram que os estabelecimentos com agroindústrias não inspecionadas possuíam maior diversidade de atividades agrícolas e não agrícolas. Esse mesmo resultado foi observado neste trabalho e também nos trabalhos de Sulzbacher e Neumann (2014).

$\mathrm{Na}$ concepção de Sulzbacher e Neumann (2014), a formalização das agroindústrias gera consequências positivas, como a geração de trabalho e renda, contudo pode comprometer a reprodução social a partir das transformações que ocorrem nas unidades de produção agropecuária, como a redução das demais atividades agrícolas para atender à demanda de trabalho nas agroindústrias, resultando na menor diversificação das propriedades.

Essa variação na estrutura produtiva, na escala de produção, bem como nas decisões entre como e quando exercer a atividade de agroindustrialização, é uma característica inerente à agricultura familiar, que busca se adequar aos contextos territorial e temporal em que se inserem (SCHNEIDER, 2010; WEISZ JUNIOR; TRENTIN; FILIPPI, 2006). Assim, a agroindústria familiar mostra-se heterogênea e diversificada e "seu surgimento está ligado às estratégias sociais e produtivas dos agricultores familiares e demais membros, sejam eles ligados por vínculos de parentescos ou de reciprocidade" (WESZ JUNIOR; TRENTIN; FILIPPI, 2006, p.5).

\subsection{PERFIL DAS MULHERES ENTREVISTADAS}

Todas as mulheres que participaram deste estudo são casadas, com faixa etária de 26 a 53 anos e média de 43 anos de idade. Somente a mais nova não possui filhos. Quanto ao grau de escolaridade, duas possuem ensino fundamental, seis possuem nível médio e duas possuem nível superior (Regina é bióloga e Paulina é pedagoga). Todas são responsáveis pelas tarefas domésticas e pelos cuidados da família. Com exceção daquelas que abandonaram a atividade de processamento do leite, todas as outras acumulam as atividades agroindustriais, além das atividades domésticas. Duas exercem, ainda, atividades não agrícolas em outros setores, sendo uma professora em escola rural e outra gerencia a loja de produtos de irrigação de propriedade da família.

A ampliação da jornada de trabalho feminina foi observada por diversos autores (BONI, 2005; PACHECO, 2009; SILIPRANDI, 2009, SCOTT; RODRIGUES; SARAIVA, 2010; SANTOS, 2016;). Segundo Boni (2005) e Scott et al. (2010), o trabalho da mulher rural vai além da dupla jornada, sendo uma jornada contínua do amanhecer ao anoitecer e ainda resultando na confusão entre as atividades domésticas e produtivas. Assim, observa-se nos resultados deste estudo, que as mulheres acumulam as tarefas domésticas e as tarefas de agroindustrialização, integrando estas últimas às primeiras, como relatado por Boni (2005). Essa naturalização do processo de agroindustrialização como uma tarefa doméstica pode ter como consequência tanto a sobrecarga de trabalho quanto a desvalorização do trabalho de agroindustrialização executado por elas, como já ocorre em relação ao trabalho doméstico.

As mulheres entrevistadas aprenderam as técnicas de processamento com suas mães, avós ou sogras, tendo complementado seu conhecimento nos cursos realizados durante o projeto executado pelos agentes de Extensão Rural do município, especialmente quanto ao conhecimento de novos produtos e às boas práticas de fabricação. Nos estudos realizados por Wesz Junior et al. (2006) em agroindústrias familiares no sul do Brasil, na maior parte das vezes, o processamento se dava por técnicas transferidas por gerações passadas, sendo 
relevante para a permanência de hábitos, costumes, cultura e saber locais, os quais, segundo esses autores, começaram a ser vistos como cruciais para a emergência de um novo modelo de produção e de consumo alimentar. Por não ter um sentido meramente econômico, a agroindústria familiar se contrapõe ao mercado uniforme, apresentando uma identidade territorial, com valorização das vocações regionais (WESZ JUNIOR; TRENTIN; FILIPPI, 2006).

\subsection{PRINCIPAIS FATORES QUE ESTIMULARAM A AGROINDUSTRIALIZAÇÃO}

\section{a) A agroindustrialização como estratégia familiar}

A pluriatividade na agricultura familiar pode ser estimulada por vários fatores, segundo Schneider (2007) e Conterato (2008). Dentre eles, os autores destacam o fato de que os agricultores inseridos no modelo do agronegócio imposto pelo sistema capitalista têm sofrido com sua vulnerabilidade diante da queda crescente e continuada das rendas agrícolas, por passarem a depender de tecnologias que oneram o custo de produção, sem necessariamente aumentar a rentabilidade e sem conseguir competir com a agricultura altamente modernizada. Essa redução na renda familiar estimula os membros das famílias a buscar outras formas de ocupação (SCHNEIDER, 2007). E este foi o principal fator motivador para as famílias deste estudo terem buscado a produção de derivados de leite como estratégia para geração de renda para a família, especialmente em momentos de crise.

Das mulheres entrevistadas, apensas duas apresentaram a atividade como forma de autonomia financeira feminina, não relacionando a decisão pela atividade a um momento de crise ou de necessidade financeira da família. As oito demais iniciaram a atividade por necessitar aumentar a renda da família, sendo que cinco delas afirmaram que a decisão ocorreu em um momento de crise financeira.

A entrevistada Simone informou que iniciou a atividade de produção de derivados do leite após a decisão do casal de abandonar o comércio que possuíam na capital do Estado do Espírito Santo, em consequência do fato de terem sido vítimas de assalto. Retornando às suas origens em busca de segurança, foram residir nas terras da família, explorando a produção de leite para o processamento, que se tornou a única fonte de renda da família por oito anos.

\footnotetext{
"Nós começamos bem devagarinho. E aí, a gente começou a tirar leite, ia junto, acordar de madrugada e ir para o curral. Ele já sabia alguma coisa, né? Ele era dessa região. E eu nunca tinha visto uma vaca de perto. Eu ajudava a tirar leite de madrugadinha e depois comecei a fazer queijo e vender por aqui mesmo. Aí, a produção estava aumentando e a gente fez uma queijaria bem simples, assim. E aí, nossa renda era só o queijo mesmo e a gente começou a vender o queijo que a gente fazia para outros lugares aqui da região. E tinha dia que eu cheguei a fazer 18 queijos. É muito. Mas, eu adorava (Simone, 44 anos, ensino médio, gerente da loja de material para irrigação pertencente à família)."
}

A produção de queijo também foi uma estratégia de emancipação da família de Marinalva diante da exploração do trabalho rural. A família vivia em uma propriedade de gado de corte, tendo o marido como empregado formal da fazenda, mas sendo o trabalho realizado por todos da família, sem a devida remuneração. $A$ 
decisão pela produção de derivados do leite representou o início da independência financeira e o resgate de perspectivas para o futuro da família.

"Eu era dona de casa, ajudava ele na fazenda, no curral. Mas, a renda era totalmente dele. Em fazenda o seu trabalho não tem início nem tem fim, só tem meio. Não tem como prosperar em fazenda dos outros, não tem futuro. Ele tinha muito medo, pois já tinha a vida estabilizada na fazenda, ele tinha medo de sair e passar fome. Eu pensava de uma forma e ele pensava de outra. A gente era presa demais. E eu queria ter minha vida e minha liberdade. Aí eu falei com ele - nós vamos sim, vamos tentar. No começo não foi fácil. Por que nada é fácil, mas nós fomos lutando (Marinalva, 41 anos, ensino médio, produtora de queijos)."

Segundo Figueiredo (2010), diante do espaço produtivo, as mulheres desenvolvem estratégias de processamento da produção que contribuem decisivamente no aumento do aproveitamento de produtos e gerando benefícios socioeconômicos, como a ampliação da diversidade de produtos consumidos e comercializados, a ocupação da força de trabalho dos membros da família e a agregação de valor aos produtos derivados da unidade produtiva familiar.

De acordo com Schneider (2010), a renda obtida com as atividades não agrícolas proporciona um incremento de renda que pode ser utilizado para o sustento da família e para investimentos na propriedade. De fato, oito das dez mulheres entrevistadas consideraram a atividade de agroindustrialização importante para a construção do patrimônio da família, para o investimento na própria agroindústria e em outras atividades agropecuárias ou para o sustento da família.

"Com o dinheiro que a gente tinha, a gente construiu nossa casa, uma casa bem bonita para a época, né? Compramos as vacas e aí a gente começou a tirar leite com as vacas lá de minha casa. [...] A gente já tinha conseguido plantar nosso café lá na baixa. [...] Aí, fomos crescendo e compramos esse comércio aqui na roça." (Simone)

"Com o dinheiro do queijo, a gente deposita e compra boi, paga os camaradas, paga uma coisa ou outra, faz compra." (Regina, 26 anos, bióloga, produtoras de queijos)

"Eu compro coisinhas para dentro de casa, né? Umas coisas que a gente precisa. Às vezes falta uma coisa, tem o dinheirinho do queijo e a gente compra, né?" (Rita, 53 anos, ensino fundamental, produtora sazonal de queijos)

"Eu, primeiro, consegui investir na construção da fábrica de queijo. Foi construída com o dinheiro de queijo, no padrão que é. Não é uma coisa enorme, mas foi construída com dinheiro de queijo, foi muito dinheiro. [...] Pagar cartão de crédito, fazer compras, farmácia..." (Nívea, 49 anos, ensino médio, abandonou a atividade de produção de queijos)

"Paga ração, energia, vaqueiro, casa agropecuária, produto para usar na ordenha, comprar as vacas, remédio para secar leite, coisa cara..." (Jussara, 49 anos, ensino médio, produtora de queijos) 
Dessa forma, o processamento de derivados do leite se mostrou como uma importante estratégia de reprodução socioeconômica para as famílias estudadas.

b) A agroindustrialização como forma de agregar valor à produção e de independência da família aos grandes laticínios

Schneider (2007) afirma que a pluriatividade é uma característica intrínseca da agricultura familiar que busca se adaptar às transformações estruturais ocorridas na agricultura. Sob esse aspecto, oito das mulheres entrevistadas apontaram a transformação do leite como uma forma de agregar valor à produção de leite e como uma alternativa ao fornecimento de leite para os laticínios. As famílias preferem não se relacionar com os grandes laticínios devido à forma oligopsônica de atuação destes no mercado, tanto pela dependência gerada, quanto pelo pagamento de valores inferiores ao custo de produção e sem direito a negociação, além do risco de ter o leite rejeitado por acidez.

"Se fosse para tirar o leite para vender para o resfriador não compensava. Então, eu faço queijo que compensa muito mais, né?" (Regina)

"E quando tem muito leite é um tal de chegar leite ácido que eu não sei de onde que vem. Antigamente era assim. Aí era aquele desespero, né? Cinquenta litros de leite vinham como ácido e quando ia receber não tinha nada, tinha pouco lá no laticínio que a gente pegava o contracheque, porque o leite estava ácido. Tinha vez que vinha cinco, seis vezes. Pagava metade, acho que era. Na época, não estava compensando vender o leite. Nem hoje também não compensa vender leite. Temos a produção pequena também. Quando você tem uma produção grande, para mexer com agroindústria, fica mais complicado, né? Mas com a produção pequena dá mais retorno, né? Agrega mais valor ao produto." (Carolina, 48 anos, ensino médio, produtora sazonal de queijos)

\footnotetext{
"Porque colocava no resfriador e ficava torcendo para o leite não voltar. Porque já teve vez que chegou a voltar, porque se der um pouquinho de acidez no resfriador, não pega. Aí eu ficava assim... meu Deus, será que vai ficar ou vai voltar esse leite? Com o coração na mão..." (Jandira, 45 anos, ensino médio, dona de casa - abandonou a atividade de produção de queijos)
}

Em um estudo realizado por Lopes et al. (2006), comparando a renda obtida com o processamento do leite em relação à venda do leite in natura para laticínios, concluiu-se que a produção e a comercialização de queijo mostraram-se mais rentáveis que a do leite. Dessa forma, os autores consideram que a agroindustrialização pode contribuir para o aumento das receitas sem alterações significativas do custo operacional efetivo da atividade leiteira, sendo uma alternativa para o incremento da renda do produtor de leite.

De acordo com Wesz Junior et al. (2006), nem sempre a agroindústria representa a atividade principal, mas nos estabelecimentos que desenvolvem a agroindustrialização, a agregação de valor ao produto primário pode duplicar a renda familiar quando comparado com propriedades onde predomina a monocultura. 


\title{
3.5 A AGROINDUSTRIALIZAÇÃO COMO ESTRATÉGIA PARA A AUTONOMIA FINANCEIRA E PARA A AUTOESTIMA DAS MULHERES
}

Embora apenas duas mulheres entrevistadas tenham apontando a atividade como forma alcançar sua autonomia financeira, foi identificado em nove entrevistas que as mulheres se sentem mais independentes financeiramente e participativas na geração de renda para a família. Esse fator contribuiu para aumentar a autoestima das mulheres, conforme os dados levantados na entrevista.

"Eu me sinto bem, né? Porque muita gente gosta. Quem compra sempre volta e é rentável também. Me sinto bem independente." (Regina)

"Eu me sinto assim... eu fico feliz, alegre, por que é bom a gente ter com que trabalhar e colocar um dinheiro dentro de casa, né? Se você tem um dinheirinho ali, você pode fazer o que você quer. Então você fica uma pessoa mais independente, né? Por que é diferente você ter e você pedir." (Rita)

\begin{abstract}
"Antes eu achava, assim, que sem o meu marido eu não ia viver, eu não tinha profissão. Eu pensava: eu tenho que aguentar isso aqui por que eu não tenho dinheiro e não sei fazer outra coisa, é ele que me sustenta. Hoje eu penso diferente. Hoje eu penso que eu dou conta, sim. Que, se ele quiser sair fora ou fazer outra coisa, eu dou conta, sim. Hoje eu tenho responsabilidade e assumo uma casa" (Marinalva)
\end{abstract}

"Eu me sinto mais útil, com mais autoestima, não dependo de ninguém" (Jandira)

Apesar de a maior parte das mulheres entrevistadas se ocupar ou ter se ocupado com a atividade de agroindustrialização com o objetivo de geração de renda para a família, Nívea e Jandira optaram pela produção de queijo para possuírem uma profissão, para renda própria e para sua autoestima. Nívea iniciou a atividade após entrar em depressão. Encontrou na agroindustrialização uma forma de ocupação de seu tempo livre, de se tornar uma profissional e de ter uma renda para realizar seus sonhos. Investiu na queijaria nos padrões estabelecidos pelo SIM, inclusive com a pasteurização do leite, e registrou sua produção, alcançando mercados na cidade. Ela mesma fazia as entregas e negociava.

"No início, a renda ficava toda para mim. [...] E depois fui juntando, consegui fazer cirurgia plástica, consegui colocar meu aparelho dentário, que era o meu sonho, fui me sentindo cada vez mais bonita e melhor" (Nívea)

A autoestima também se refletiu no investimento em estética por Jandira. Apesar de não participar nas decisões relacionadas às finanças da família, Jandira tinha as próprias vacas, pagava o vaqueiro com recursos oriundos de sua renda da venda de queijos e também uma empregada doméstica para ter seu tempo livre para dedicar-se à agroindústria.

"Olha, eu sempre fui muito vaidosa, né? Então sempre gostei de ir ao dermatologista. Quando eu inventei fazer minha cirurgia, eu fiz em duas etapas, né? Eu fiz primeiro a mama, 
depois o abdômen, e tudo com esse dinheiro. E roupas, calçados, tudo, médico, tudo, tudo com o dinheiro meu. Foi muito importante (a produção de queijo) porque senão eu não teria conseguido fazer o que eu fiz. Principalmente minha cirurgia. Jamais eu faria, porque ele (o marido) sempre foi contra. Eu com o meu dinheiro, ele já não era a favor. Falava assim: "Porque não precisa, está bom assim". Então, você acha que se ele fosse pagar, eu teria feito?" (Jandira)

Metade das mulheres possui ou possuía renda própria oriunda da atividade. Dessas, duas iniciaram a atividade para geração de renda exclusivamente para a sua autonomia (Nívea e Jandira), detendo total domínio sobre a renda gerada, embora não exerçam mais a atividade. As outras três (Marinalva, Joana e Jussara) retiram uma porcentagem do valor obtido para uso pessoal. No entanto, todas afirmaram que também utilizam a sua renda para pequenas despesas do lar, como alimentos, vestuário para a família, utensílios domésticos.

Para Souza e Silva (2012) o desenvolvimento da atividade de agroindustrialização pelas mulheres resulta em geração de renda monetária que pode se tornar a principal fonte ou auxiliar no complemento da renda familiar, contribuindo para aumentar a autoestima das mulheres que passam a ser mais valorizadas perante a sociedade. Além disso, o envolvimento das mulheres na pluriatividade contribui para romper os padrões das relações de poder exercidos pelo homem, gerando autonomia e evitando o êxodo feminino para o meio urbano. Essa autonomia pode estar relacionada ao processo de tomadas de decisões, pois elas passam a estar presentes nas esferas reprodutivas e produtivas.

Diferentemente das observações de Souza e Silva (2012), nem sempre a geração de renda pelas mulheres rurais se traduz em sua autonomia financeira e decisória. Das sete mulheres que ainda produzem queijo e que utilizam a renda para o sustento da família, apenas duas participam do processo decisório do destino da renda (Marinalva e Jussara). Ou seja, cinco mulheres dependem da autorização do marido para a utilização dos recursos oriundos da atividade, inclusive aquela que retira parte da renda para uso pessoal (Joana). Sobre este aspecto, é possível afirmar que o processo decisório, de forma geral, ainda depende do homem e que, quando a atividade ganha representatividade na renda da família, muitas vezes passa para o domínio masculino, tanto no aspecto de precificação e negociação, quanto na alocação dos recursos humanos da família (BONI, 2005; SILIPRANDI, 2015; PACHECO, 2009).

Questionada sobre quem decide sobre o valor do produto e o destino da renda, Rita foi enfática ao responder: "Ele decide, eu não!". Da mesma forma respondeu Regina: "É ele, mas ele me pergunta". Resposta semelhante foi dada por Marinalva, que, embora participe da decisão sobre o destino da renda, acrescentou a decisão exclusiva do marido de registrar a agroindústria com o nome fantasia fazendo referência ao seu próprio apelido, a despeito do sobrenome da família.

"Ele que decide (o preço). Eu prefiro deixar ele com essa parte, porque geralmente as pessoas que vêm comprar queijo procuram por ele, querem negociar com ele, querem falar com ele. Porque as placas que nós colocamos nas estradas está o nome e o telefone dele. Porque foi ele que registrou no nome dele a queijaria. [...] Não perguntou nada pra gente. O certo seria o nome da família, mas ele começou a mexer e ele colocou o nome dele. [...] Eu acho um absurdo isso. Eu não gostei. Eu acho que como está a família toda unida no queijo, tinha que estar o nome da família na empresa" (Marinalva) 
A mesma situação foi observada na entrevista com Joana que admite que é o marido quem decide o valor da produção, bem como o destino da renda.

"Ele que fala o valor. Tem vezes que eu falo que está barato. [...] Ele que vende, só que o dinheiro que ele vende lá (no supermercado) eu não vejo, não sei o que ele está fazendo. O que eu vendo aqui (na porta de casa) é meu, mas se eu não vender eu não tenho. [...] Às vezes eu quero fazer uma coisa, quero tirar minha carteira (de motorista), aí não dá pra eu tirar, porque fica difícil pra pagar. Eu tenho que comprar as coisas para aqui para casa." (Joana, 39 anos, ensino fundamental, produtora de queijos)

Para Bourdieu (2002, p. 9), as diferenças de gênero são produto de construção do social do que é ser mulher e do que é ser homem. Assim, as divisões dos papéis sociais se naturalizam por meio da construção de valores, comportamentos e símbolos que impõem uma condição desigual e desprivilegiada da mulher em relação ao homem (BOURDIEU, 2002; HERNÁNDEZ, 2009).

Diversos pesquisadores (BONI, 2005; ZORZI, 2008, PACHECO, 2009; SILIPRANDI, 2009; SCOTT; RODRIGUES; SARAIVA, 2010) afirmam que a divisão sexual do trabalho e o poder de decisão na pequena propriedade é de caráter patriarcal, sendo chefiada pelo homem - o "chefe da família" -, que determina a distribuição das funções, em uma hierarquia de gênero e de geração. E essa característica é passada de geração para geração, tornando-se naturalizada e legitimada pela sociedade.

Boni (2005) considera que a mudança comportamental ou a incorporação de outros papeis além dos de mãe, esposa e trabalhadora, não depende apenas das mulheres, pois a socialização da mulher rural foi e é muito rígida. Para essa pesquisadora, a mulher foi educada para aceitar a dominação masculina, sem o direito de intervir em decisões por eles tomadas, mesmo quando não concordam. Segundo Zorzi (2008), esse comportamento evidencia o limite da autonomia feminina nas relações sociais no espaço rural.

De acordo com Boni (2005) e Siliprandi (2009), devido à normalização na distribuição das tarefas - cabendo às mulheres as atividades domésticas e reprodutivas e aos homens as atividades financeiras e produtivas - ocorre uma exclusão da mulher da sua participação nas decisões, além da desvalorização do seu trabalho, o qual é considerado como uma "ajuda" sem direito à remuneração.

A atividade de agroindustrialização, apesar de ser reconhecida pela maioria das mulheres como uma forma de independência financeira, ainda é encarada como uma "ajuda", tanto pelas próprias mulheres quanto pelos seus maridos. Todas afirmaram que "ajudam" o marido nas despesas do lar ou que "ajudam" na principal atividade financeira da família. Para as famílias de Simone, Regina, Marinalva, Joana, Nívea, Paulina e Jussara, a atividade de produção de derivados do leite representa, ou representou em algum momento da vida, a principal atividade geradora de renda para a família. Em todas as famílias a atividade produtiva é desempenhada pelas mulheres, sendo que somente Marinalva e Paulina recebem auxílio na limpeza das instalações. Enquanto que todas acumulam a atividade doméstica, sem participação deles.

"Eu ajudo na queijeira, eu ajudo no atendimento ao cliente, eu sou simpática, eu trato todo mundo super bem. Se eu posso fazer isso, por que eles não podem me ajudar na casa? Mas 
ele não concorda, meu marido tem pavor, ele fala que é injusto um homem lavar um prato. Ele não gosta" (Marinalva)

\begin{abstract}
"Eu acordo seis horas e a correria começa, né? Faço o café, se tiver roupa para lavar eu lavo logo a roupa. Meu marido chega com o leite e a gente prepara, né? Aí, antes de fazer o queijo eu faço o almoço. Aí faço o queijo, tomo meu banho rapidinho e vou para a escola. [...] Tem mulher que não sai pra fora para ajudar o homem, entendeu?" (Paulina, 39 anos, pedagoga, professora de educação infantil em um distrito do município de Linhares e produtora de queijos)
\end{abstract}

No processo de comercialização, somente três mulheres (Regina, Nívea e Jussara) negociam e comercializam sua produção em mercados locais, padarias e supermercados. As demais não saem de casa para esta função, comercializando somente "na porta de casa". O comércio externo é função do marido, sendo esta mais uma forma do homem ficar em evidência no processo produtivo e manter o controle sobre a família.

Diferentemente das demais entrevistadas, Carolina foi a única mulher que afirmou não gostar da atividade. Sendo uma produtora sazonal, a produção de queijos é determinada pelo marido e a renda é de uso comum, não tendo autonomia sobre o valor que é gerado.

\begin{abstract}
"Depende dele (do marido). Se tiver que fazer, eu faço. Não gosto muito porque dá muito trabalho. Tem que acordar cedo, um tal de lava-lava, limpa-limpa, que tem que ser. Olhando por um lado, (a produção de queijo) é importante porque ajuda na renda da casa. E por outro lado é mais trabalho. Por mim, só venderia o leite, mas num preço bom como a gente vende na feira. [...] Não tem outra coisa pra fazer, o gado é importante, ele (o marido) gosta. Então se ele gosta do gado de leite, se sobrar eu tenho que fazer queijo. Gosto de muita coisa na roça, mas não de ficar fazendo queijo." (Carolina)
\end{abstract}

Conforme Schneider (2010), a decisão pela pluriatividade parte dos indivíduos interessados ou da família. No entanto, observou-se que o ingresso e a permanência na atividade estão também relacionados a uma decisão do "chefe da família" em detrimento do desejo das mulheres. Somente Marinalva, Nívea, Paulina, Jussara e Jandira decidiram ou sugeriram 0 ingresso na atividade de agroindustrialização. As demais iniciaram a atividade e permanecem nela por uma decisão do marido.

Mesmo sob o domínio masculino, as mulheres ainda são capazes de reagir em situações extremas. Marinalva é responsável por toda a produção do queijo, única atividade geradora de renda da família. Mas, nem sempre foi assim. Anteriormente, o marido possuía parceria com o pai, da qual não conseguia garantir o sustento total dos seus, enquanto Marinalva trabalhava em uma escola e sua renda era destinada parcialmente para o sustento da família. Após uma enchente em que a família perdeu a maior parte do gado de leite, Marinalva tomou a decisão de conduzir toda a produção, exonerando-se de sua função pública e assumindo a agroindústria. Decidiu pela compra de matéria prima produzida pelos vizinhos e se desfez da sociedade com o sogro. Observa-se, neste caso, o potencial feminino diante das adversidades econômicas e sua capacidade de resiliência. 
"Ele (o marido) trabalhava com o pai dele tirando leite, então eu não queria me meter nisso, que era ele e o pai dele. Eu não podia me meter como me meto hoje, né? Então eu achei melhor eu ter a minha independência. Fui trabalhar como coordenadora da escola, aí veio a enchente. Como eu te disse, nós dependíamos do queijo, né? Então, não tinha queijo. Acabou, a enchente levou tudo, não tinha onde botar o gado. Depois disso, eu quis tomar as rédeas de tudo e não ser mais empregada. Era salário mínimo, não era satisfatório, e aqui a gente ganha muito mais do que isso, né? Mesmo comprando o leite. O pai dele saiu e nós entramos para tomar conta de tudo. [...] Eu decidi sozinha." (Marinalva)

De acordo com Siliprandi (2009), as mulheres rurais contribuem significativamente com o sustento das famílias enquanto provedoras de alimentos, sendo, muitas vezes, as primeiras a reagirem contra a privação e às mudanças no acesso aos meios de sobrevivência.

\subsection{AS EXPECTATIVAS DAS MULHERES - FRUSTRAÇÕES E REALIZAÇÕES}

Apesar de reconhecerem a importância da produção de derivados do leite para sua autonomia financeira ou para a geração/ampliação da renda da família, três mulheres abandonaram a atividade e outras três desejam fazê-lo. Todas relacionaram a ideia à necessidade de produção constante e ao acúmulo de atividades (responsabilidade do cuidado do lar).

"Nós paramos por que nossa loja cresceu. E aí acabou. A renda ficou melhor e também a pessoa cansa demais mexer com esse negócio de leite e queijo. É todo dia, todo dia, todo dia. Aí, fica cansando." (Simone)

"Era que eu estava cansada. De tanto bater queijo sozinha e com esforço repetitivo, aí as minhas articulações todas estavam com problemas. Aí eu estava fazendo fisioterapia. Então, eu achei que ia piorar mesmo. Então, eu falei para o meu marido se era para eu ficar gastando fora com fisioterapia por causa de um trabalho repetitivo, que foi comprovado porque quando eu parei sumiram todas as minhas dores. Aí eu falei para ele calcular, fazer as contas entre eu fazer queijo e arrendar (a propriedade)." (Nívea)

"Para mim era uma terapia até, assim, quando estava tudo certinho. Eu tinha uma menina que cuidava da minha casa e eu só fazia o queijo. Aí, a partir do momento que você precisa cuidar da casa e fazer o queijo, aí já não é mais uma terapia, entende? Aí já vira outra coisa, já vira perturbação e eu não queria isso para mim. Posso até voltar atrás. Eu posso até a voltar a fazer. Não é uma decisão, assim: não quero mais, entendeu? [...] Eu falava assim: eu quero parar, porque produzir queijo é uma coisa que desgasta muito. Como a gente não tinha resfriador, eu nunca parei, eu nunca tive sábado, nunca tive um domingo. Pensa, dentro de 15 anos você não ter uma semana livre de queijo." (Jandira)

Após deixar as atividades agroindustriais, Simone passou a se dedicar aos afazeres domésticos e a gerenciar a loja de material de irrigação da família, 
localizado no meio rural. A maior parte da propriedade da família de Nívea foi arrendada para terceiros; sua atividade, agora, é administrar os recursos familiares, bem como cuidar dos afazeres domésticos, enquanto o marido trabalha como intermediário no mercado agrícola, mantendo, ainda, a produção de suínos na propriedade rural. Jandira vendeu suas vacas e emprestou o valor arrecadado ao próprio marido, recebendo mensalmente o valor de $1 \%$ do total em juros, enquanto ele permanece nas atividades agropecuárias e os filhos conduzem as atividades no comércio de material de construção da família. Para ela, esse valor é o suficiente para suas despesas "supérfluas" [sic] e ela pode se dedicar ao cuidado dos seus. No entanto, todas elas admitem que a atividade de agroindustrialização foi importante para a realização dos sonhos pessoais e de construção do patrimônio da família.

Foi possível observar que essas mulheres apresentaram em comum a autodeterminação de rejeitar uma atividade no momento em que elas se mostraram menos atrativas, uma vez que a decisão de sair da atividade partiu diretamente delas. Outra característica das famílias dessas mulheres é o fato de a pluriatividade intersetorial ter se apresentado como uma estratégia reprodutiva que sustentou a opção das mulheres pelo abandono da pluriatividade para-agrícola. Apesar dessa "nova configuração" de atividades nas famílias, pode-se dizer que não ocorreu uma perda da identidade da agricultura familiar, uma vez que foram mantidos seus vínculos rurais, adequando-se às oportunidades e à realidade estrutural em que estão inseridas (SCHNEIDER, 2007; WESZ JUNIOR; TRENTIN; FILIPPI, 2006).

A necessidade de produção diária do queijo aliada à ideia da possibilidade de melhores rendas e de menor carga horária de trabalho em ocupações não agrícolas parecem ter importância direta na decisão das mulheres, pois o desejo de sair da atividade apresentado por Joana, Carolina e Jussara está diretamente relacionado à possibilidade de acesso a uma atividade não agrícola, especialmente nos setores de serviço e comércio.

\begin{abstract}
"Porque eu não vou ficar fazendo queijo o resto da vida. Tem hora que eu penso até em parar e fazer outro serviço diferente. [...] Talvez, se aparecesse uma coisa melhor, eu pensava em até ir. Mas, ficava difícil para mim. [...] Uma coisa melhor é um serviço que eu não precise ficar todo dia, pelo menos sábado e domingo eu ia estar folgada. Pode ser que eu ia ganhar talvez mais, né? [...] Só que eu ia ter outros benefícios, né? Eu ia ter férias e, vamos supor que eu arrumasse um serviço que trabalha só de segunda até sexta, sábado e domingo eu não trabalhava..." (Joana)
\end{abstract}

"Eu gostaria de ter arrumado um emprego fora, mas não deu. [...] Para ter uma renda maior um pouquinho. Porque na roça a gente trabalha, mas é mais complicado. Qualquer emprego, vendedora em loja..." (Carolina)

"Mas, eu tenho vontade de parar, porque é muito puxado. Não tem sábado, não tem domingo, não tem dia santo. Eu queria montar uma loja." (Jussara)

Nos trabalhos desenvolvidos por Boni (2005), observou-se situação semelhante em que, ao mesmo tempo em que as mulheres perceberam os benefícios gerados pela produção agroindustrial familiar, elas queixaram da impossibilidade de usufruir desses benefícios, devido ao acúmulo de trabalho, incluindo os finais de semana. No entanto, Boni (2005) afirma que o investimento em aquisição de equipamentos, como resfriadores, possibilita o armazenamento do leite 
nos fins de semana e seu processamento na segunda-feira. A autora conclui que há diversas possibilidades de ajustes que permitem que as mulheres participem da vida comunitária e mantenham seu lazer.

No entanto, há também quem utilize a atividade de acordo com sua necessidade, sem a obrigatoriedade do desempenho. É o caso de Rita, que produz de forma sazonal e sem pretensões de crescimento econômico.

\begin{abstract}
"Eu penso de fazer mais coisas, só que assim, a gente já está mais de idade, mais cansada, né? Então, eu pensei assim, parei por aqui mesmo. Vou fazendo aos pouquinhos. Não quero crescer, fazer muitas coisas não, porque eu já estou muito cansada. E eu sou sozinha, é muito serviço para mim." (Rita)
\end{abstract}

A sazonalidade na produção também foi relatada por Sulzbacher e Neumann (2014). Para esses autores, a produção sazonal não configuraria como um trabalho gerador de renda, sendo confundido com trabalho doméstico desenvolvido pelas mulheres da propriedade. A renda gerada dessa atividade sazonal é destinada para atender as demandas de consumo diário ou atendimento às necessidades básicas da família, corroborando os achados deste estudo. Os autores ainda concluíram que muitas vezes as famílias não apresentam o interesse de crescer economicamente dentro da lógica industrial, por preferirem a "tranquilidade da propriedade, a lida com a terra e com animais" (SULZBACHER; NEUMANN, 2014, p.117).

Contrariamente à maioria das entrevistadas, Regina, Marinalva e Paulina consideram a produção de derivados de leite a principal renda da família e persistem na atividade, apesar das adversidades. A família de Marinalva possui a atividade de agroindustrialização como única fonte de renda da família, tendo desistido da ocupação não agrícola intersetorial para se dedicar exclusivamente à atividade de processamento do leite, reconhecendo nessa atividade a melhor opção para geração de renda. Já Paulina acumula as atividades domésticas, de produção de queijo e de funcionária pública em uma escola - sendo esta última relacionada à sua realização pessoal - e a atividade de agroindustrialização a principal atividade econômica da família.

\begin{abstract}
"A produção de queijo é muito importante, é a renda principal, com certeza. Se não fosse o queijo eu não sei nem o que seria da gente. [...] Eu comecei a estudar, fiz pedagogia. Esse ano eu consegui como auxiliar de professor [...] mas, no ano que vem, se Deus quiser, eu vou estar na sala de aula como professora. [...] A gente está sempre aprendendo. Eu adoro mexer com criança, adoro trabalhar com criança, porque a minha é educação infantil." (Paulina)
\end{abstract}

O envolvimento das mulheres no processo produtivo contribuiu para externar os sonhos e expectativas de Simone, Marinalva, Nívea, Paulina e Jandira, uma vez que ter uma importante atividade geradora de renda para a família desenvolvida por elas, influenciou no surgimento de novas relações sociais. $O$ desenvolvimento da atividade gerencial na loja da família por Simone, o tomar a frente das atividades agroindustriais por Marinalva, a realização do sonho de se sentirem mais belas por meio de procedimentos estéticos por Nívea e Jandira e a realização do sonho profissional de Paulina demonstram novas ruralidades que se inserem no espaço rural, que não perdeu a sua essência. Não se pode atribuir um 
aspecto de descaracterização do rural o exercício de uma atividade não agrícola, como a agroindustrialização, bem como a mudança comportamental que acompanha esse processo de inserção das mulheres no espaço produtivo e comercial. Para Carneiro (2012), o rural não deve ser reconhecido somente como um espaço de produção de bens materiais, associado à produção de alimentos e de matéria prima para servir às agroindústrias urbanas, mas como uma fonte de bens simbólicos, como a cultura e as expressões do saber - aqui se enquadrando a transformação artesanal de alimentos, como o queijo, cujo saber fazer passou por gerações - ressignificados em uma nova dinâmica econômica e social.

\section{CONSIDERAÇÕES FINAIS}

As estratégias de reprodução das famílias estudadas evidenciaram a utilização da diversificação da produção por meio da pluriatividade, seja ela pela agroindustrialização ou pelo ingresso em setores não agrícolas, diante das adversidades do contexto capitalista em que as famílias se inserem. A participação das mulheres foi fundamental nas relações intrafamiliares, especialmente na divisão do trabalho na pluriatividade, resultando na criação de seu espaço produtivo e econômico.

Foi possível concluir que, apesar de as mulheres não participarem efetivamente do processo decisório relacionado à alocação dos membros da família na pluriatividade desenvolvida no estabelecimento, bem como no destino da renda obtida com a atividade agroindustrial desenvolvida por elas, ainda assim as mulheres, em sua maioria, se sentem úteis e valorizadas por sua contribuição na renda familiar.

Não se pode afirmar que a agroindustrialização contribuiu efetivamente para a autonomia financeira feminina, haja vista que, na maior parte das vezes, as mulheres dependem da autorização ou do conhecimento do marido para a utilização da renda gerada com a atividade, evidenciando a forte cultura patriarcal que ainda se preserva nos espaços rurais. Apesar disso, é possível afirmar, também, que o envolvimento da mulher em atividades geradoras de renda para a família contribuiu para ampliar suas relações sociais e elevar sua autoestima; e que, em alguns casos, a participação da mulher nessas atividades contribuiu para a mudança de comportamento e no estabelecimento de novas ruralidades, evidenciando a constante mudança e reestruturação da cultura local pela incorporação de novos valores no espaço rural.

Provavelmente, o envolvimento dessas mulheres em circuitos de economia solidária poderia contribuir para o desenvolvimento de sua capacidade gerencial e ampliar os espaços de discussão e de negociação para elas, o que poderia resultar em maior autonomia. Mas, a questão das relações de gênero intrafamiliares, envolvendo a divisão sexual do trabalho, dependeria de um processo mais sistemático de mudança de paradigmas enraizados na sociedade. E, nesse ponto, a Extensão Rural pode contribuir para o processo, por meio de ações participativas de problematização e construção do conhecimento.

Não se pretendeu com este estudo generalizar ou esgotar a discussão sobre a importância da agroindustrialização como estratégia de reprodução familiar rural e de emancipação feminina, mas estimular a reflexão sobre a geração de renda e relações de gênero nas famílias rurais. Estudos mais abrangentes e envolvendo o papel da Extensão Rural no processo de pluriatividade e de emancipação feminina são necessários para ampliar a reflexão sobre os novos contextos rurais e as novas ruralidades que se estabelecem. 


\section{REFERÊNCIAS}

BARDIN, L. Análise de conteúdo. Lisboa: Edições 70. 1977. 225p.

BONI, V. Produtivo ou reprodutivo: o trabalho das mulheres nas agroindústrias familiares - um estudo na região oeste de Santa Catarina. 2005. 99f. Dissertação (Mestrado em Sociologia Política) - Programa de Pós-Graduação em Sociologia Política, Universidade Federal de Santa Catarina.

BRUMER, A. Gênero e agricultura: a situação da mulher na agricultura do Rio Grande do Sul. Estudos Feministas, Florianópolis, v. 12, n. 1, p. 205-227, 2004.

CARNEIRO, M. J. Do "rural" como categoria de pensamento analítico e como categoria analítica. In: CARNEIRO, M. J. (org.). Ruralidades Contemporâneas: modos de viver e pensar o rural na sociedade brasileira. Rio de Janeiro: Mauad X/Faperj, 2012.

CONTERATO, M. A. Dinâmicas regionais do desenvolvimento rural e estilos de agricultura familiar: uma análise a partir do Rio Grande do Sul. 2008. 290f. Tese (Doutorado em Desenvolvimento Rural) - Programa de Pós-Graduação em Desenvolvimento Rural, Universidade Federal do Rio Grande do Sul.

FIGUEIREDO, M. A. B. Una estrategia de desarrollo local desde las experiencias agroecológicas de la región cañera pernambucana - Brasil. 2010. 273 f. Tesis (Doctorado en Agroecología) - Programa de Doctorado en Agroecología, Universidad de Córdoba.

LOPES, M. A. et al. Análise de rentabilidade de uma empresa com opção de comercialização de queijo ou leite. Arquivos Brasileiros de Medicina Veterinária e Zootecnia, v. 58, n. 4, p. 642-647, 2006.

MARTINE, G. A trajetória da modernização agrícola: a quem beneficia? Lua Nova, n. 23. p. 7-37, 1991.

MIOR, L. C. Agricultura familiar, agroindústria e desenvolvimento territorial. 2011. Disponível em: http://nmd.ufsc.br/files/2011/05/Mior_Agriculturafamiliar_agroindustria_e_desenvolvimento_territorial.pdf. Acessado em: 04 jun. 2016.

PACHECO, M. E. L. Os caminhos das mudanças na construção da Agroecologia pelas mulheres. Agriculturas: Experiência em Agroecologia, Rio de Janeiro, v. 6, n. 4, p. 4-8, 2009.

REDIN, E. Estratégias de reprodução na agricultura familiar - um campo em permanente construção. ACTA Geográfica, Boa Vista, v. 6, n. 13, p. 155-173, 2012.

SANTOS, N. A. A divisão sexual do trabalho na agricultura familiar: entre a invisibilidade e a desvalorização do trabalho (re)produtivo de mulheres trabalhadoras rurais do município de Brejo/MA frente à expansão da monocultura de soja. Revista de Políticas Públicas, São Luís, Número Especial, p. 331-337, 2016. 
SCHNEIDER, S. A pluriatividade no meio rural brasileiro: características e perspectivas para investigação. 2007. Disponível em: http://portal.mda.gov.br/dotlrn/clubs/redestematicasdeater/diversificaonaagriculturafa miliarfumicultura/contents/photoflow-view/content-view?object_id=884960. Acessado em 04 jun. 2016.

A pluriatividade na agricultura familiar, 2.ed. Porto Alegre: Editora da UFRGS, 2010.

SCOTT, P.; RODRIGUES, A. C.; SARAIVA, J. C. Onde mal se ouvem os gritos de socorro: notas sobre a violência contra a mulher em contextos rurais. In: SCOTT, P.; CORDEIRO, R.; MENEZES, M. (Orgs). Gênero e geração em contextos rurais. Ilha de Santa Catarina: Ed. Mulheres, 2010.

SILIPRANDI, E. Mulheres e agroecologia: a construção de novos sujeitos políticos na agricultura. 2009. 291 f. Tese (Doutorado em Desenvolvimento Sustentável) Programa de Pós-Graduação em Desenvolvimento Sustentável, Universidade de Brasília.

Mulheres e agroecologia: transformando o campo, as florestas e as pessoas. Rio de Janeiro: Editora UFRJ, 2015.

SILVA, J. M.; MENDES, E. P. P. Agricultores familiares e reprodução social: as comunidades Cruzeiros dos Martírios e Paulistas no município de Catalão (GO). In: NEVES, A.F. et al. (orgs.). Coletânea Interdisciplinar em Pesquisa, PósGraduação e Inovação. v 1. [livro eletrônico]. São Paulo: Blucher, 2015.

SOUZA, R. E. M.; SILVA, M. G. S. N. Mulher: A quebra do paradigma da função reprodutiva. Revista Geografares, n.10, p.203-224, 2012.

SULZBACHER, A. W.; NEUMANN, P. S. O social e suas dimensões em agroindústrias familiares rurais. Extensão Rural, Santa Maria, v.21, n.3, p. 93-120, 2014.

VINHA, M. B. et al. Fatores socioeconômicos da produção de queijo minas frescal em agroindústrias familiares de Viçosa, MG. Ciência Rural, v. 40, n. 9, p. 20232029, 2010.

WESZ JUNIOR, V. J.; TRENTIN, I. C. L.; FILIPPI, E. E. A importância da agroindustrialização nas estratégias de reprodução das famílias rurais. In: Congresso da Sociedade Brasileira de Economia e Sociologia Rural, 44., 2006, Fortaleza, CE. Anais... Fortaleza: SOBER/BNB, 2006.

ZORZI, A. Uma análise crítica da noção de empoderamento com base no acesso das agricultoras ao Pronaf Mulher em ljuí-RS. 2008. 137 f. Dissertação (Mestrado em Sociologia) - Programa de Pós-Graduação em Sociologia. Universidade Federal do Rio Grande do Sul. 